\title{
Spatial distribution of pregnancy in adolescence and associations with socioeconomic and social responsibility indicators: State of Minas Gerais, Southeast of Brazil
}

\author{
Distribuição espacial da gravidez adolescente e associações \\ com indicadores socioeconômicos e de responsabilidade social: \\ estado de Minas Gerais, sudeste do Brasil
}

Original Article

Keywords

Pregnancy in adolescence Health status indicators Spatial analysis Bayes Theorem Models, biological

Palavras-chave

Gravidez na adolescência Indicadores básicos de saúde Análise espacial

Teorema de Bayes Modelos biológicos

\section{Abstract}

PURPOSE: To describe associations between pregnancy rates in adolescence and socioeconomic and social responsibility indicators in the municipalities of the State of Minas Gerais, Southeast of Brazil, in the year of 2010. METHODS: Ecological study using data from the Brazilian Live Birth Information System (SINASC). The percentage of live births to adolescent mothers (LBAM) for each municipality was calculated based on the quotient between number of born alive infants of mothers aged 10-19 years old and total number of live births in the year of 2010. Fully Bayesian models were used to obtain the percentages of LBAM adjusted for spatial effects and to assess possible associations with socioeconomic and social responsibility indicators. RESULTS: The crude percentage of LBAM for the total number of live births in the municipalities of Minas Gerais in 2010 ranged from 0 to $46.4 \%$, with median percentage being $19.6 \%$ and the first and third quartiles being 15.6 and $23.1 \%$, respectively. This study has demonstrated a close relationship between adolescent pregnancy and socioeconomic indicators. LBAM percentages were found to be higher in municipalities with low population density, low human development index and other low development indicators. CONCLUSION: The strong relationship between LBAM percentages and socioeconomic indicators suggests that adolescent pregnancy is more a social than a biological problem. Therefore, programs and actions should go beyond sexual education and information on preventive health methods.

\section{Resumo}

OBJETIVO: Descrever as associações entre os percentuais de gravidez na adolescência e indicadores socioeconômicos e de responsabilidade social dos municípios do estado de Minas Gerais, sudeste do Brasil, no ano de 2010. MÉTODOS: Estudo ecológico, utilizando dados do Sistema de Informações sobre Nascidos Vivos (SINASC). O percentual de nascidos vivos de mães adolescentes (LBAM) para cada município foi calculado segundo o quociente entre o número de nascidos vivos de mães com idade entre 10 e 19 anos e o número total de nascidos vivos registrados no ano de 2010. Modelos totalmente bayesianos foram utilizados para a obtenção de percentuais de LBAM ajustados por efeitos espaciais e para avaliar as possíveis associações com os indicadores socioeconômicos e de responsabilidade social. RESULTADOS: Os percentuais brutos de LBAM em relação ao total de nascidos vivos nos municípios de Minas Gerais no ano de 2010 variaram de 0 a 46,4\%, com uma mediana de 19,6\%. O primeiro e o terceiro quartis são, respectivemente, 15,6 e 23,1\%. O estudo evidenciou uma estreita relação entre a gravidez na adolescência e indicadores econômicos e sociais. Os percentuais de LBAM se mostraram maiores nos municípios com menor tamanho populacional, menores valores do Índice de Desenvolvimento Humano e menores valores de outros indicadores de desenvolvimento. CONCLUSÃO: A forte relação entre os percentuais de LBAM e os indicadores sociais e econômicos sugerem que a gravidez adolescente é muito mais um problema social que biológico. Os programas e as ações devem ir muito além de educação sexual e informações sobre métodos preventivos de saúde.

Correspondence

Edson Zangiacomi Martinez Av. Bandeirantes 3900 - Monte Alegre CEP: 14049-900 Ribeir̃̃o Preto (SP), Brazil

Received $06 / 17 / 2015$

Accepted with modification $07 / 08 / 2015$
Department of Social Medicine, Faculdade de Medicina de Ribeirão Preto, Universidade de São Paulo - USP - Ribeirão Preto (SP), Brazil. Department of Social Medicine, Faculdade de Medicina de Ribeirão Preto, Universidade de São Paulo - USP - Ribeirão Preto (SP), Brazil. Conflict of interests: none. 


\section{Introduction}

Due to its high prevalence, adolescent pregnancy is no longer seen as a social problem only, being now considered an important public health issue ${ }^{1}$. Studies show that there are several causes and consequences of an early pregnancy, highlighting social, economic, educational and behavioural factors ${ }^{1-4}$. In fact, some studies suggest that pregnancy in adolescence can be influenced not only by individual characteristics but also by economic, social and educational structures of the community where the adolescent is inserted ${ }^{5}$. The effects of the neighbourhood features influence behaviours, attitudes, values and opportunities. These components of the ecological models consider people within the context of several environments or ecological systems in which they live, such as family, relationships, neighbourhood, community and institutions like schools and workplaces. These models are based on the premise that individuals cannot be studied without taking into account the various ecological systems in which they live ${ }^{6}$. As people are geographically grouped, the analysis incorporating the group structure allows behaviours and values to be considered ${ }^{7}$.

In the literature on health care, there are a great amount of studies using ecological models which are based on an approach formulated by Bronfenbrenner ${ }^{8}$ for the ecology of human development. This author, in the end of the 1970s, provided important premises for the scientific field regarding the development and planning of research studies in natural environments by criticising the then traditional way of studying the human development. For him, these investigations were limited to focusing only on the individual developing within a restricted and static environment, without the due consideration of the multiple environmental influences in which the subjects lived $^{8}$. Thus, Bronfenbrenner ${ }^{8}$ delineated a theoretical model which can be seen as a set of hierarchical systems in which the larger encompasses the smaller, analogously to the traditional Russian dolls (matroschka). According to the author, the ecological research should contain data on the largest number of systems in which the subject is inserted. In this way, the ecological approach of human development gives privilege to longitudinal studies, highlighting instruments which enable both description and understanding of systems as contextualised as possible. An ecological study is considered as such when aspects regarding the systems and their possible influences are not ignored during the research and discussion of the results.

The use of an ecological model in the study on adolescent pregnancy aims to investigate not only the factors involved but also regional, socioeconomic and social responsibility factors in the community which can affect early pregnancy ${ }^{9}$. In this way, this approach can help healthcare managers better plan their actions for birth control among adolescents, as well as actions for income distribution, labour market and development of the State. With a nationwide range, the project called "Nascer no Brasil" (Birth in Brazil: National Survey into Labor and Birth ${ }^{10}$ has become an example of reference and great repercussion by addressing themes such as maternal mortality, prenatal care, type of delivery for adolescents, calculation of gestational age, relationships between parturient and at-risk neonate, and other issues addressing the country's current scenario ${ }^{11}$. However, up to now, this project does not include studies on the relationships between adolescent pregnancy and geographic space.

Because of their relevance to the public healthcare, ecological research works using a spatial approach have been object of several studies conducted in Brazil. For instance, Nogueira et al. ${ }^{2}$ conducted a study to analyse the spatial distribution of adolescent pregnancy in the city of Belo Horizonte, State of Minas Gerais, reporting the presence of conglomerates with high rates of adolescent mothers in association with lower socioeconomic conditions. Considering the State of São Paulo, Martinez et al. ${ }^{12}$ performed an ecological study using spatial analysis of adolescent pregnancy and local socioeconomic characteristics. The study showed that early pregnancy is higher in those municipalities with lower population density, lower Gross National Product (GNP) per capita, lower human development index and higher poverty rate. In addition, Martins et al. ${ }^{13}$ conducted an ecological study with spatial focus on healthcare micro-regions in the State of Mato Grosso and they found that fecundity among adolescent women is higher in micro-regions with low indicators of education and socioeconomic development. In this same context, an ecological study ${ }^{14}$ aiming to identify the pattern of birth profile in Vale do Paraíba (State of São Paulo, Brazil) showed that the proportion of adolescent mothers is higher in municipalities with less education and less infrastructure.

In the present ecological study, we have hypothesised that both geographic residence location and community in which these adolescent mothers are inserted greatly contribute to their early pregnancy. Therefore, the objective is to find an association between percentage of live births to adolescent mother (LBAM) and socioeconomic and social responsibility factors in the municipalities of the State of Minas Gerais in the year of 2010. The percentages of LBAM for each municipality of the State of Minas Gerais were estimated by using empirical (i.e. crude percentages directly obtained from data with no adjustment or smoothing) approaches, as well as fully Bayesian methods, considering data available from the Live Birth Information System (SINASC, acronym for the system in Portuguese, Sistema de Informações sobre Nascidos Vivos) 
in 2010. The analysis results are shown in the tables and graphs elsewhere in the article.

\section{Methods}

Comprising 853 municipalities, the State of Minas Gerais is the fourth largest in territory and the second most populated in Brazil, with approximately 20 million inhabitants. Minas Gerais is marked by profound asymmetries regarding the geographic distribution of economic, social and cultural characteristics as the majority of the poorer municipalities are located in the North and Northeast areas of the State, whereas the municipalities with higher human development indexes are located in the South and Central areas ${ }^{15}$.

The following characteristics of the 853 municipalities of the State of Minas Gerais were used: Minas Gerais Social Responsibility Index (MGSRI) and its dimensions (social assistance, culture and education, sports and tourism, municipal finances, basic sanitation, dwelling and environment, income and employment, healthcare and public security) as proposed by the João Pinheiro Foundation; Municipal Human Development Index (MHDI) and its dimensions (education, longevity and income); Firjan Municipal Development Index (FMDI) and its dimensions (employment and income, education and health); Unified Health System Development Index (IDSUS) and its dimensions (access and effectiveness), population size (in number of inhabitants according to the second 2010 demographic census performed by the Brazilian Institute of Geography and Statistics (IBGE); GNP per capita (values in Brazilian real currency, 2010); Gini’s Index (measurement of the degree of income concentration in which the values range from 0 to 1 , with the latter corresponding to maximum inequality); and percentage of families benefited by the Bolsa Família Program (BFP) in each municipality. The BFP is a Brazilian social assistance policy created in 2004 aiming at aiding families in poverty and extreme poverty situations ${ }^{16}$.

Data on adolescent pregnancy were obtained from the SINASC ${ }^{17}$. This health information system was implemented in Brazil in 1990 for obtaining profiles of the born alive infants according to variables considered important within the epidemiological context ${ }^{18}$. It is based on information contained in the live birth certificates, which is an official standard form to be obligatorily issued by hospitals and other healthcare facilities where delivery is performed ${ }^{19}$. For each municipality, the LBAM percentage was calculated based on the quotient between the number of born alive infants of mothers aged 10-19 years old and total number of live births in the year of 2010 .

The MGSRI was created by the João Pinheiro Foundation in order to detect the development level of the 853 municipalities of the State of Minas Gerais regarding education, health, public security, income and employment, demographic data, management, dwelling, infra-structure and environment, culture, and leisure and sports. To obtain the MGSRI, the indicators were transformed into indexes ranging from 0 to 1 as a result of the division between the lowest value observed and the total width between the highest and lowest values observed in the period under analysis. Data are available in the electronic site of the João Pinheiro Foundation (www.fjp.mg.gov.br).

The MHDI is derived from the HDI used by the United Nations Development Program (UNDP). This index comprises indicators which can affect the quality of life of the inhabitants of a municipality, being calculated by the arithmetic mean of three components: education, longevity and income. Education takes into account the municipality's illiteracy rate and the rate of matriculation in all education levels. Longevity is based on life expectance, whereas income is given by the municipality's GNP adjusted to the local currency. A list of MHDI for Brazilian municipalities regarding the year of 2010 is available in the electronic site of the UNDP (www.pnud.org.br). The overall MHDI and its components are standardised into a scale from 0 to 1 , with higher values indicating higher levels of development.

The FMDI aims to monitor yearly the socioeconomic development of a region considering the different realities based on the values by municipality. The FMDI includes three dimensions: employment and income, education and health, all having equal weight in the calculation of the development index of Brazilian municipalities. The FMDI ranges from 0 to 1 , with values nearer to 1 meaning higher level of development in the municipality. These data are available in the following electronic page: www.firjan.org.br/ifdm.

The IDSUS evaluates the Brazilian public healthcare system in terms of universality of access, integrality of health care, regionalisation and hierarchization. This index measures the difficulties of access to healthcare and effectiveness of the results based on the best responses. The IDSUS ranges from 0 to 10 , with higher values indicating higher levels of public healthcare development in the region. These data were obtained from the electronic page idsus.saude.gov.br.

Statistical analysis of the data uses a Bayesian model similar to one suggested by Martinez et al. ${ }^{12}$, who considered that for the municipality $i, Y_{i}$ is the counting of LBAM, $N_{i}$ is the known total number of live births and $\theta_{i}$ is the percentage of LBAM. Thus, $Y_{i}$ is a random variable following a binomial distribution formally written by: $\mathrm{Y}_{\mathrm{i}} \mid \mathrm{N}_{\mathrm{i}}, \theta_{\mathrm{i}} \sim \operatorname{Binomial}\left(\mathrm{N}_{\mathrm{i}}, \theta_{\mathrm{i}}\right), \mathrm{i}=1, \ldots, \mathrm{M}$, where $\mathrm{M}=853$ is the number of municipalities. 
Assuming a logit link function between the percentage $\theta_{i}$ of LBAM and a given observation $\mathrm{x}_{\mathrm{i}}$ of an independent quantitative variable $\mathrm{X}$, we have the following: $\theta_{i}=\frac{\exp \left[\alpha+\beta\left(x_{i}-\bar{x}\right)+\gamma_{i}\right]}{\text {, }}$ $\theta_{i}=\frac{1+\exp \left[\alpha+\beta\left(x_{i}-\bar{x}\right)+\gamma_{i}\right]}{2}$ where $\overline{\mathrm{x}}$ is the arithmetic mean of the set of observations $\mathrm{x}_{1}, \mathrm{x}_{2}, \mathrm{x}_{853}, \alpha$ and $\beta$ are unknown parameters (fixed effects) and $\gamma_{i}$ is a random effect associated with the i-th municipality. The spatial distribution adopted for $\gamma_{i}$ follows a conditional autoregressive (CAR) model $^{20}$, in which the criterion used for neighbourhood definition was that of adjacency in which municipalities having boundaries with each other were considered neighbours.

We used the GeoBUGS module ${ }^{21}$ of the software WinBUGS ${ }^{22}$ package to implement the model, considering that the fixed effect $\alpha$ follows an improper flat prior distribution, the fixed effect $\beta$ follows a non-informative normal distribution, with mean 0 and variance 1000 , and the parameter $\sigma_{\gamma}^{2}$ follows an inverse gamma prior distribution, expressed as $\sigma_{\gamma}^{-2} \sim \operatorname{Gamma}(0,5 ; 0,0005)$, as recommended by Thomas et al. ${ }^{21}$. We assume independence between the prior parameters, and computations are performed using a Markov chain Monte Carlo (MCMC) method. All results were based on samples of 100,000 realizations, collected by saving the current state after every $100^{\text {th }}$ iteration and after a burn-in period of 10,000 samples. Models with and without the random effects $\gamma_{j}$ were compared using the deviance information criterion (DIC) ${ }^{23}$. Models with low DIC values are to be preferred over those with higher values. The Bayesian models were fitted by considering one covariable at a time. It was not possible to include multiple covariables into only one model because of the strong presence of collinearity among them. The limitations resulting from the collinearity found in the fit of multiple models within the spatial context are discussed by Morgenstern ${ }^{24}$.

The present research project has been approved by the local research ethics committee of the Clinics Hospital of the Ribeirão Preto Medical School in terms of ethical aspects and scientific content (HCFMRP Process $\left.\mathrm{n}^{\circ} 10157 / 20\right)$.

\section{Results}

The percentages of LBAM in relation to the total of live births in the municipalities of Minas Gerais in 2010 ranged from 0 to $46.4 \%$, with median percentage being $19.6 \%$ and the first and third quartiles being 15.6 and $23.1 \%$, respectively. Figure 1 shows a map with crude percentages of LBAM for the 853 municipalities of Minas Gerais for the year of 2010 . These percentages were divided into four categories, as follows: two categories with values below the median and two categories with values above the median. One can observe a heterogeneous distribution of the LBAM percentages as the highest values are concentrated in the North of the State and the lowest values mostly in the South. Only $4.2 \%$ of the municipalities of Minas Gerais had crude percentages below 10\%, whereas $17.9 \%$ had percentages above $25 \%$. Among the highest percentages, 6 municipalities had values above $40 \%$, namely: Mathias Lobato ( $40.4 \%)$, located at the region of the Vale do Rio Doce (Western of the State); Comendador Gomes (40.7\%) and Veríssimo (44.2\%), both located at the region of Triângulo Mineiro/Alto Paranaíba (Eastern of the State); Santa Fé do Sul (41.3\%) and Ponto Chique (41.4\%), both located at the Northern of the State; and Santo Hipólito (46.4\%), located at the central region of Minas Gerais.

Statistical models using spatial data structure showed values lower than DIC values compared to those without it (values not showed). This suggests that models presenting spatial structure are more adequate for the data of this study. Figure 2 shows the map of smoothed LBAM percentages estimated by a Bayesian model with spatial effect and without insertion of covariables. These results thus emphasize the deep discrepancies which exist among these percentages when North and South regions of the State are compared.

The results shown in Table 1 were obtained with a fully Bayesian model with spatial structure and including the socioeconomic and social responsibility indicators as

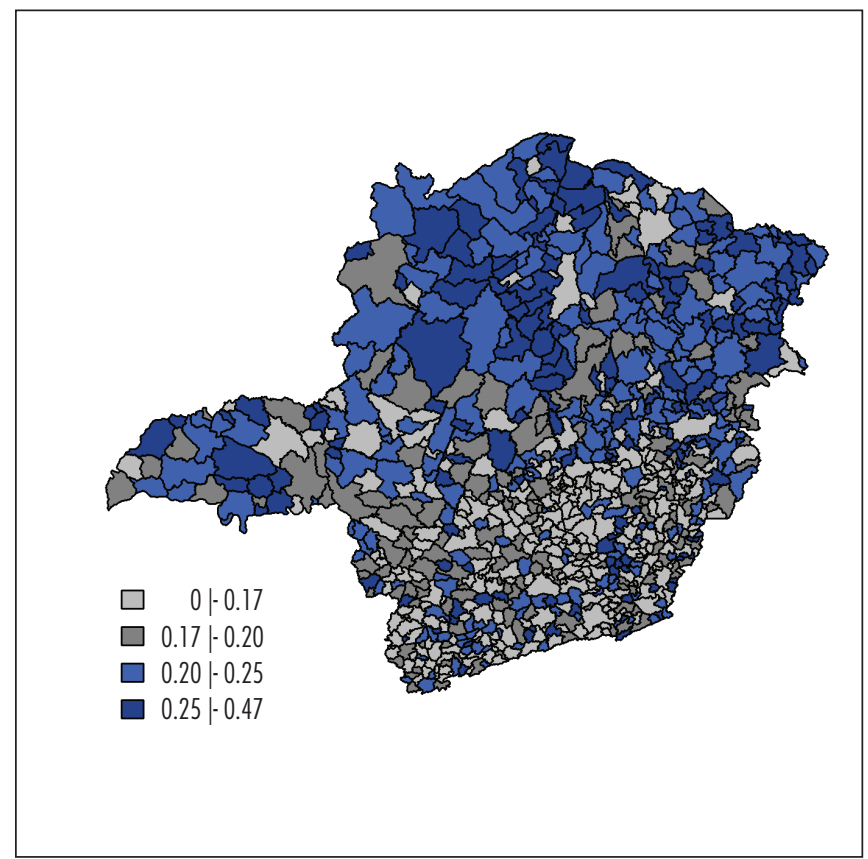

Figure 1. Spatial distribution of the crude percentages of live births to adolescent mother, State of Minas Gerais, Brazil, 2010 
covariables. Each independent variable was represented by indicator variables (also called dummy variables), thus allowing the estimation of mean percentages in each one of the classes and ratios between percentages of LBAM with their respective $95 \%$ credible intervals. Credible intervals without including 1 indicate significant associations with percentages of LBAM (indicated by asterisks in the Table). To facilitate the comparisons between the percentages, only those reference classes with lower LBAM percentages were used. In these tables, each indicator shows very different value widths for its dimensions, which made it difficult to build intervals of equal classes, except the FMDI. Therefore, the grouping of values into class intervals was based on the histogram of their distributions so that each one of its extremes had no more than $5 \%$ of the municipalities, thus facilitating comparisons. Table 1 shows the associations between adolescent pregnancy and overall MGSRI and overall FMDI. With regard to MGSRI, this index has ten dimensions and among them five ones (culture, education, municipal finances, public security, and overall MGSRI) were associated with adolescent pregnancy (complete results are given in the supplementary material). However, social assistance, sports and tourism, basic sanitation, dwelling and environment, income and employment, and health were not associated with the percentages of LBAM. With regard to the FMDI, all the four dimensions were significantly associated with adolescent pregnancy (complete results are given in the supplementary material). It was observed that the lower the values of MGSRI and FMDI,

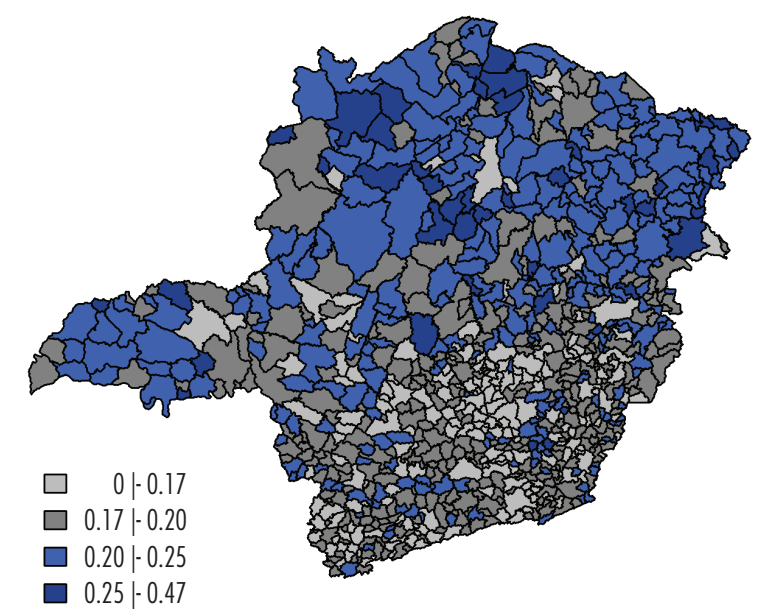

Figure 2. Spatial distribution of the smoothed percentages of live births to adolescent mother, obtained from the fully Bayesian model in the absence of covariables, State of Minas Gerais, Brazil, 2010 the higher the percentage of LBAM in each municipality. For instance, in the overall MGSRI, the reference class is represented by higher values and, when compared to values of the interval $0.44-0.50$, one can observe a percentage ratio of 1.583 . Therefore, one can observe $58.3 \%$ more cases of LBAM in the municipalities having MHDI values below 0.50 than in those having MGSRI above 0.65 , and so on.

Table 1 also shows the associations between the overall MHDI and adolescent pregnancy (results for the three MHDI dimensions are given in the supplementary material). It was observed that the frequency of LBAM is higher in municipalities having lower MHDI values. According to the global MHDI, $64.7 \%$ of the municipalities of Minas

Table 1. Percentages of live births to adolescent mothers in according to the Minas Gerais Social Responsability Index (MGSRI), Firjan Municipal Development Index (FMDI), overall Municipal Human Development (MHDI), population size and percentage of families benefited by the Bolsa Família Program (BFP) - Minas Gerais, Brazil, 2010

\begin{tabular}{|c|c|c|c|c|c|}
\hline & \multirow{2}{*}{ n } & \multicolumn{2}{|c|}{ Percentages of LBAM } & \multicolumn{2}{|c|}{ Percentage ratios } \\
\hline & & Estimates & $95 \% \mathrm{Crl}$ & Estimates & $95 \% \mathrm{Crl}$ \\
\hline \multicolumn{6}{|l|}{ Overall MGSRI } \\
\hline $0.44 \mid-0.50$ & 33 & 23.9 & $22.1-25.9$ & 1.58 & $1.42-1.75^{\star}$ \\
\hline $0.50 \mid-0.55$ & 188 & 21.6 & $20.8-22.3$ & 1.43 & $1.32-1.54^{\star}$ \\
\hline $0.55 \mid-0.60$ & 338 & 18.9 & $18.4-19.5$ & 1.25 & $1.16-1.35^{\star}$ \\
\hline $0.60 \mid-0.65$ & 256 & 17.7 & $17.2-18.2$ & 1.17 & $1.08-1.26^{*}$ \\
\hline $0.65 \mid-0.70$ & 38 & 15.2 & $14.1-16.2$ & 1.000 & Reference \\
\hline \multicolumn{6}{|l|}{ Overall FMDI } \\
\hline$<0.40$ & 6 & 21.8 & $18.0-25.9$ & 1.47 & $1.20-1.78^{\star}$ \\
\hline $0.40 \mid-0.60$ & 285 & 20.8 & $20.1-21.4$ & 1.41 & $1.29-1.52^{\star}$ \\
\hline $0.60 \mid-0.80$ & 537 & 18.5 & $18.1-18.9$ & 1.25 & $1.16-1.35^{\star}$ \\
\hline$\geq 0.80$ & 25 & 14.8 & $13.7-15.9$ & 1.00 & Reference \\
\hline \multicolumn{6}{|l|}{ Overall MHDI } \\
\hline $0.50 \mid-0.60$ & 73 & 22.0 & $20.8-23.2$ & 1.50 & $1.39-1.61^{*}$ \\
\hline $0.60 \mid-0.65$ & 228 & 21.5 & $20.8-22.1$ & 1.46 & $1.38-1.55^{\star}$ \\
\hline $0.65 \mid-0.70$ & 324 & 19.3 & $18.8-19.8$ & 1.32 & $1.24-1.39 *$ \\
\hline $0.70 \mid-0.75$ & 187 & 17.8 & $17.3-18.3$ & 1.22 & $1.15-1.28^{\star}$ \\
\hline $0.75 \mid-0.82$ & 41 & 14.7 & $14.0-15.3$ & 1.00 & Reference \\
\hline \multicolumn{6}{|l|}{$\begin{array}{l}\text { Population size } \\
\text { (number of inhabitants) }\end{array}$} \\
\hline$<20.000$ & 675 & 19.7 & 19.3-20.1 & 1.47 & $1.24-1.73^{\star}$ \\
\hline $20.000 \mid-50.000$ & 112 & 19.2 & $18.6-19.9$ & 1.43 & $1.21-1.68^{*}$ \\
\hline $50.000 \mid-100.000$ & 37 & 16.5 & $15.6-17.4$ & 1.23 & $1.03-1.45^{\star}$ \\
\hline $100.000 \mid-500.000$ & 25 & 15.7 & $14.7-16.7$ & 1.17 & $0.98-1.38$ \\
\hline$\geq 500.000$ & 4 & 13.5 & $11.4-15.8$ & 1.00 & Reference \\
\hline \multicolumn{6}{|l|}{ BFP } \\
\hline $0 \mid-10$ & 29 & 15.1 & $14.1-16.2$ & 1.00 & Reference \\
\hline $10 \mid-20$ & 263 & 17.1 & $16.6-17.5$ & 1.13 & $1.05-1.21^{*}$ \\
\hline $20 \mid-30$ & 262 & 19.5 & $18.9-20.1$ & 1.29 & $1.19-1.29^{*}$ \\
\hline $30 \mid-40$ & 240 & 21.2 & $20.6-21.9$ & 1.41 & $1.30-1.52^{\star}$ \\
\hline $40 \mid-50$ & 59 & 23.6 & $22.1-25.1$ & 1.56 & $1.41-1.72^{\star}$ \\
\hline
\end{tabular}

95\% Crl: 95\% Credible Interval.

*Significant differences from the reference class are indicated by an asterisk.

LBAM: Live births to adolescent mother 
Gerais are ranked as of medium development. On the other hand, $74.4 \%$ of the municipalities were ranked as of very low and low development based on education. The municipalities ranked as of very low development based on education were found to have $52.8 \%$ more cases of LBAM than those ranked as of high development regarding this dimension (values from 0.7 to 0.8 ).

Municipalities with low population size had higher frequency of LBAM (Table 1). In the State of Minas Gerais in $2010,79.1 \%$ of the municipalities had less than 20,000 inhabitants and $3.4 \%$ had more than 100,000 inhabitants, with large urban centres being characterised by more availability of healthcare access and higher income per capita. The small-sized municipalities had $47.3 \%$ more cases of adolescent pregnancy compared to the large-sized ones.

Table 1 shows a direct association between percentage of families benefiting from the Bolsa Família Program and percentage of LBAM. On the other hand, IDSUS and its dimensions (i.e. accessibility and effectiveness), Gini's Index, and GNP per capita were not shown to be associated with percentages of LBAM in the State of Minas Gerais in 2010 (results not listed in the Table).

\section{Discussion}

Adolescent pregnancy is common worldwide ${ }^{25}$ and it has been widely associated strongly with low educational level, lack of partner support, low number of prenatal visits, late onset of prenatal care, low birth weight and prematurity $^{26,27}$. The problems persist beyond the postpartum stage, given that the maternal and child mortality tend to be higher in the poorest group of adolescents and with the lowest educational level, which is ruled by the lack of personal and financial resources and appropriate social support for the exercise of motherhood ${ }^{28}$. Many of the published studies have focused primarily on identifying individual and risk factors ${ }^{29}$, but a number of ecological studies ${ }^{12-14}$ have reported deep relations between teenage pregnancy and environmental factors. In this context, the present study has evidenced a significant association between adolescent pregnancy and socioeconomic indicators in the Brazilian State of Minas Gerais. The percentages of LBAM were found to be higher in municipalities with lower population size, high percentage of families benefiting from the Bolsa Família Program, and lower values of MHDI, MGSRI and FMDI.

The crude percentages of LBAM (Figure 1) were found to have a spatial distribution pattern, showing that municipalities located in the North of the State tend to have higher values, whereas municipalities in the South of the State tend to have lower values. This trend is highlighted in the map of LBAM smoothed percentages obtained the fully Bayesian model (Figure 2). Knowing the regional discrepancies in the socioeconomic and healthcare indicators of the State of Minas Gerais as Northern and Northeastern regions have lower levels of development than those found in the Southern region, one can observe that these profound asymmetries have some effect on the phenomenon of adolescent pregnancy. Moreover, the Northern of the State comprises the Vale do Jequitinhonha, described by Stefani et al. ${ }^{29}$ as the poorer and the least developed region of the State.

The present study highlights the strong association between LBAM and education indicators, a finding which is corroborated by the literature as other authors report a strong correlation between low education level and a trend towards adolescent motherhood ${ }^{30}$. A study by Almeida and Aquino ${ }^{31}$ showed that elementary education is often not finished by girls with history of adolescent pregnancy. Jorge et al. ${ }^{32}$ reported that there is also a relationship between low education level and recurrence of pregnancy during adolescence in association with the social vulnerability experienced by these girls. In addition, a study by Martins et al. ${ }^{13}$ showed that low education level is a factor exposing adolescent girls to unplanned pregnancy. As an important consequence, the deep relationship between education and early pregnancy contributes to the maintenance of poverty, since pregnant adolescents tend to leave the school system and do not return later. This decreases the chances of getting high-paying jobs.

We also have found some evidence that low public security levels are associated with higher percentages of LBAM. A global study ${ }^{33}$ of adolescents aged $15-19$ years living in disadvantaged urban settings in five different cities (Baltimore, USA; Johannesburg, South Africa; Ibadan, Nigeria; New Delhi, India; and Shanghai, China) found a similar pattern. In this study, the odds of ever being pregnant were found to increase with more observed neighbourhood violence and with greater perceived fear of being robbed or attacked. In addition, the article from Copping et al. ${ }^{34}$ supports the argument that the perception of violence, sexual precocity and adolescent pregnancy are jointly connected with the local environmental conditions.

In summary, the present study reinforces the notion that the adolescent pregnancy is a complex phenomenon associated with numerous economic, educational, social, environmental and behavioural factors. Like other social phenomena, the frequency of their occurrence differs by regions and social groups, and possible solutions for the reduction of the percentages of LBAM go far beyond health issues alone. The problem has a wide range of complexity, and more efficient results would be obtained by actions that enhance or optimize the different resources of municipalities and compensate previous social differences, as previously pointed by Martinez et al. ${ }^{12}$. 
A potential limitation of the present study relies on the fact that the information obtained from SINASC may not be homogeneous throughout the State of Minas Gerais, a situation also occurring in other Brazilian states ${ }^{35}$. A study ${ }^{36}$ evaluating the SINASC data from 132 municipalities of Minas Gerais in 2010 showed that the system was not adequately implemented in the majority of the municipalities evaluated, highlighting lack of qualified professionals, poorly filled forms for live birth certificates, poor data gathering, underuse of data and insufficient publicising of information. In addition, due its design, the results and findings of this study can be affected by ecological bias, in which an observed association between clusters of individuals do not necessarily mean that the same association occurs at the level of individuals. However, the results here found have great compatibility with those of studies that do not use ecological models, and this reinforces the hypothesis that the environment where an adolescent lives can favour an early pregnancy. On the other hand, although these limitations may importantly affect the findings of the present study, one can conclude that adolescent pregnancy is much more a social than a biological problem, and, as such, programs and actions should go far beyond sexual education and information on preventive health methods.

\section{Acknowledgements}

To Brazilian research-funding agencies Coordenadoria de Aperfeiçoamento de Pessoal de Nível Superior (CAPES) (Process number 4576/2014-04), CNPq (Process number 305942/2012-3) and Fundação de Apoio ao Ensino, Pesquisa e Assistência (FAEPA) (Process number 658/2015).

\section{References}

1. Cunha AA, Monteiro DL. Gravidez na adolescência como problema de saúde pública. In: Monteiro DL, Cunha AA, Bastos AC, organizadores. Gravidez na adolescência. Rio de Janeiro: Revinter; 1998. p. 31-42

2. Nogueira M, Silva BF, Barcelos SM, Schall VT. [Analysis of the spatial distribution of adolescent pregnancy in the city of Belo Horizonte]. Rev Bras Epidemiol. 2009; 12(3):297-312. Portuguese.

3. Gama SG, Szwarcwald CL, Leal MC. [Pregnancy in adolescence, associated factors, and perinatal results among low-income post-partum women]. Cad Saúde Pública. 2002; 18(1):153-61. Portuguese.

4. Chalem E, Mitsuhiro SS, Ferri CP, Barros MC, Guinsburg R, Laranjeira R. [Teenage pregnancy: behavioral and socio-demographic profile of an urban Brazilian population]. Cad Saúde Pública. 2007;23(1): 177-86. Portuguese.

5. Gold R, Kawachi I, Kennedy BP, Lynch JW, Connell FA. Ecological analysis of teen birth rates: association with community income and income inequality. Matern Child Health. 2001;5(3):161-7.

6. Brooks-Gunn J, Duncan GJ, Klebanov PK, Sealand N. Do neighborhoods influence child and adolescent development? Am J Sociol. 1993;99(2):353-95.

7. Susser M. The logic in ecological: I. The logic of analysis. Am J Public Health. 1994;84(5):825-9.

8. Bronfenbrenner U. Toward an experimental ecology of human development. Am Psychol. 1977;32(7):513-31.

9. Corcoran J, Franklin C, Bennett P. Ecological factors associated with adolescent pregnancy and parenting. Soc Work Res. 2000;24(1):29-39.

10. Leal MD, Gama SG. Birth in Brazil. Cad Saúde Pública. 2014;30(Supl 1):S5.

11. Vasconcellos MT, Silva PL, Pereira AP, Schilithz AO, Souza Junior PR, Szwarcwald CL. Sampling design for the birth in Brazil: National Survey into Labor and Birth. Cad Saúde Pública. 2014;30(Supl 1):S49-S58.

12. Martinez EZ, Roza DL, Caccia-Bava MC, Achcar JA, Dal-Fabbro AL. [Teenage pregnancy rates and socioeconomic characteristics of municipalities in São Paulo State, Southeast Brazil: a spatial analysis]. Cad Saúde Pública. $2011 ; 27(5): 855-67$. Portuguese.
13. Martins PC, Pontes ER, Paranhos Filho AC, Ribeiro AA. [Adolescent pregnancy: an ecological study in the health micro-regions of the State of Mato Grosso do Sul, Brazil - 2008]. Epidemiol Serv Saúde. 2014;23(1):91-100. Portuguese.

14. Hau LC, Nascimento LF, Tomazini JE. [Geoprocessing to identify the pattern of birth profile in Vale do Paraíba]. Rev Bras Ginecol Obstet. 2009;31(4):171-6. Portuguese.

15. Batella WB, Diniz AM. [Spatial analysis of violent crime determinants in Minas Gerais State]. Soc Nat. 2010;22(1):151-63. Portuguese.

16. Tavares PA. [The impact of the Bolsa Família Program on the labor supply of working mothers]. Econ Soc. 2010;19(3):613-35. Portuguese.

17. Mello Jorge MH, Gotlieb SL, Soboll ML, Almeida MF, Latorre MR. [Evaluation of the information system on live-births and of the use of its data in epidemiology and health statistics]. Rev Saúde Pública. 1993;27(Supl: 1-46). Portuguese.

18. Mello Jorge MH, Laurenti R, Gotlieb SL. [Quality analysis of Brazilian vital statistics: the experience of implementing the SIM and SINASC systems]. Ciênc Saúde Coletiva. 2007;12(3):643-54. Portuguese.

19. Pedraza DF. [Quality of the Information System on Live Births / SINASC: a critical analysis of published studies]. Ciênc Saúde Coletiva. 2012;17(10):2729-37. Portuguese.

20. Besag J, Kooperberg CL. On conditional and intrinsic autoregressions. Biometrika. 1995;82(4):733-46.

21. Thomas A, Best N, Lunn D, Arnold R, Spiegelhalter D. GeoBUGS user manual. Cambridge: MRC Biostatistics Unit; 2004.

22. Lunn DJ, Thomas A, Best N, Spiegelhalter D. WinBUGS - a Bayesian modelling framework: concepts, structure, and extensibility. Stat Comput. 2000; 10(4):325-37.

23. Spiegelhalter DJ, Best NG, Carlin BP, Van der Linde A. Bayesian measures of model complexity and fit. J R Stat Soc Series B Stat Methodol. 2002;64(Pt 4):583-639.

24. Morgenstern H. Ecologic studies in epidemiology: concepts, principles, and methods. Annu Rev Public Health. 1995;16:61-81.

25. Singh S, Darroch JE. Adolescent pregnancy and childbearing: levels and trends in developed countries. Fam Plann Perspect. 2000;32(1):14-23. 
26. Santos NL, Costa MC, Amaral MR, Vieira GO, Bacelar EB, Almeida $\mathrm{AH}$. [Teenage pregnancy: analysis of risk factors for low birth weight, prematurity and cesarean delivery]. Ciênc Saúde Coletiva. 2014;19(3):719-26. Portuguese.

27. Martins MG, Santos GH, Sousa MS, Costa JE, Simões VM. [Association of pregnancy in adolescence and prematurity]. Rev Bras Ginecol Obstet. 2011 1;33(11):354-60. Portuguese.

28. Silva JL, Surita FG. [Pregnancy in adolescence: current situation]. Rev Bras Ginecol Obstet. 2012;34(8):347-50. Portuguese.

29. Stefani J, Nunes MA, Matos R. [IMRS and its dynamics in the planning region Jequitinhonha/Mucuri]. Cad Geogr. 2014;24(41):17-33. Portuguese.

30. Kliksberg B. O contexto da juventude na América Latina e no Caribe: as grandes interrogações. Rev Adm Pública. 2006;40(5):909-42.

31. Almeida MC, Aquino EM. Adolescent pregnancy and completion of basic education: a study of young people in three state capital cities in Brazil. Cad Saúde Pública. 2011 ;27(12):2386-400.
32. Jorge MG, Fonseca SC, Silva KS, Costa SF. [Recurrent pregnancy in adolescents users of the Unified Health System]. Adolesc Saúde. 2014;11(3):22-31. Portuguese.

33. Brahmbhatt $H$, Kagesten $A$, Emerson $M$, Decker MR, Olumide $A O$, Ojengbede $O$, et al. Prevalence and determinants of adolescent pregnancy in urban disadvantaged settings across five cities. J Adolesc Health. 2014; 55(6 Suppl):S48-57.

34. Copping LT, Campbell A, Muncer S. Violence, teenage pregnancy, and life history: ecological factors and their impact on strategydriven behavior. Hum Nat. 2013;24(2):137-57.

35. Silva LP, Moreira CM, Amorim MH, Castro DS, Zandonade E. [Evaluation of the quality of data in the Live Birth Information System and the Information System on Mortality during the neonatal period in the state of Espírito Santo, Brazil, between 2007 and 2009]. Ciênc Saúde Coletiva. 2014;19(7):2011-20. Portuguese.

36. Guimarães EA, Hartz ZM, Loyola Filho Al, Meira AJ, Luz ZM. [Evaluating the implementation of Information System on Live Births in municipalities of Minas Gerais, Brazil]. Cad Saúde Pública. 2013;29(10):2105-18. 